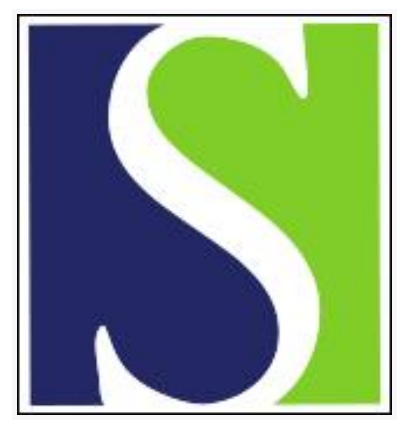

Scand J Work Environ Health 2014;40(5):511-517

https://doi.org/10.5271/sjweh.3436

Published online: 19 May 2014, Issue date: 01 Sep 2014

Occupational exposure to solvents and acute myeloid leukemia: a population-based, case-control study in four Nordic countries

by Talibov M, Lehtinen-Jacks S, Martinsen JI, Kjærheim K, Lynge E, Sparén $P$, Tryggvadottir $L$, Weiderpass E, Kauppinen T, Kyyrönen P, Pukkala E

This is currently the largest case-control study to assess the relationship between solvent exposure and acute myeloid leukemia. By linking occupational records with a job exposure matrix (JEM), we generated quantitative estimates for 26 work-related agents. It enabled us to control for a joint effect of multiple agents and variation of exposure over time.

Affiliation: School of Health Sciences, University of Tampere, Fl-33014, Tampere, Finland. Madar.Talibov@uta.fi

Key terms: acute myeloid leukemia; aromatic hydrocarbon solvent; benzene; cancer; case-control study; JEM; job exposure matrix; leukemia; Nordic Occupational Cancer Study; occupational exposure; solvent; toluene; trichloroethylene

This article in PubMed: www.ncbi.nlm.nih.gov/pubmed/24840289 


\title{
Occupational exposure to solvents and acute myeloid leukemia: a population-based, case-control study in four Nordic countries
}

\author{
by Madar Talibov, MSc, ${ }^{1}$ Susanna Lehtinen-Jacks, PhD, ${ }^{1}$ Jan Ivar Martinsen, ${ }^{2}$ Kristina Kjærheim, PhD, ${ }^{2}$ \\ Elsebeth Lynge, PhD, ${ }^{3}$ Pär Sparén, PhD, ${ }^{4}$ Laufey Tryggvadottir, PhD, ${ }^{5}$ Elisabete Weiderpass, PhD, ${ }^{2,4,6,7}$ \\ Timo Kauppinen, PhD, ${ }^{8}$ Pentti Kyyrönen, ${ }^{9}$ Eero Pukkala, PhD ${ }^{1,9}$
}

Talibov M, Lehtinen-Jacks S, Martinsen JI, Kjærheim K, Lynge E, Sparén P, Tryggvadottir L, Weiderpass E, Kauppinen T, Kyyrönen P, Pukkala E. Occupational exposure to solvents and acute myeloid leukemia: a populationbased, case-control study in four Nordic countries. Scand J Work Environ Health. 2014;40(5):511-517. doi:10.5271/sjweh.3436

Objective The aim of the current study was to assess the relation between occupational exposure to solvents and the risk of acute myeloid leukemia (AML).

Methods Altogether, this study comprises 15332 incident cases of AML diagnosed in Finland, Norway, Sweden, and Iceland from 1961-2005 and 76660 controls matched by year of birth, sex, and country. Occupational records were linked with Nordic Occupational Cancer Study job exposure matrix (JEM) to estimate quantitative values for 26 occupational exposure factors. Hazard ratios (HR) with 95\% confidence intervals ( $95 \%$ CI) were estimated by using conditional logistic regression models.

Results We did not observe statistically significantly increased risk for exposure to any of the solvents. HR estimates for high levels of toluene (HR 1.35, 95\% CI 0.74-2.46), aromatic hydrocarbon solvents (ARHC) (HR $1.18,95 \%$ CI 0.76-1.86), and moderate-to-high levels of trichloroethylene were slightly but non-significantly elevated. We did not observe an association between benzene exposure and AML in this study.

Conclusions This study did not provide clear evidence for an association between occupational solvent exposure and AML. There was some indication for an excess risk in the groups of workers exposed to toluene, trichloroethylene, and ARHC.

Key terms aromatic hydrocarbon solvent; benzene; cancer; JEM; job exposure matrix; Nordic Occupational Cancer Study; toluene; trichloroethylene.

Acute myeloid leukemia (AML) is a cancer of blood and bone marrow. It accounts for approximately $25 \%$ of all leukemias among adults (1).

While the etiology of AML is poorly understood, it has been linked to genetic disorders, physical and chemical exposures, radiation exposure, chemotherapy, and viruses $(2,3)$.
There is a general consensus that benzene can cause AML in humans (4-8). Some previous studies suggested an association between exposure to solvents and AML (9-11).

The aim of this study was to assess the relation between occupational solvent exposure and AML.

1 School of Health Sciences, University of Tampere, Tampere, Finland.

2 Cancer Registry of Norway, Oslo, Norway.

3 Centre of Epidemiology and Screening, Institute of Public Health, University of Copenhagen, Copenhagen, Denmark.

4 Department of Epidemiology and Biostatistics, Karolinska Institute, Stockholm, Sweden.

5 Icelandic Cancer Registry, Reykjavik, Iceland.

6 Institute of Community Medicine, University of Tromsø, Tromsø, Norway.

7 Samfundet Folkhälsan, Helsinki, Finland.

8 Finnish Institute of Occupational Health, Helsinki, Finland.

9 Finnish Cancer Registry, Institute for Statistical and Epidemiological Cancer Research, Helsinki, Finland.

Correspondence to: Madar Talibov, School of Health Sciences, University of Tampere, FI-33014, Tampere, Finland. [E-mail: Madar.Talibov@ uta.fi] 


\section{Methods}

The current study employed a case-control design nested in the Nordic Occupational Cancer Study (NOCCA) cohort. The NOCCA cohort consists of 14.9 million individuals from Finland, Iceland, Norway, Denmark, and Sweden who participated in population censuses in 1960, 1970, 1980/1981, and/or 1990. As we had no access to the individual records from Denmark, their data were not included.

Occupational information was obtained from computerized census records from 1960 and later censuses in Sweden and Norway and from 1970 and later censuses in Finland. In Iceland, the only computerized census record was available for 1981 census. Personal identity codes were used to link census records with the data from cancer registries and national population registries for information on cancer, death, and emigration. Each person was followed-up until the date of emigration, death or 31 December of the following years: 2005 in Finland, 2004 in Iceland, 2003 in Norway, 2003 in Denmark, and 2005 in Sweden. A detailed account of the NOCCA cohort was given in Pukkala et al (12).

All incident AML cases diagnosed from 1961-2005 were extracted from the NOCCA cohort. Five controls per case were randomly selected among persons who were alive and free from AML on the date of diagnosis of the case (hereafter the "index date" of the case-control set). Cases and controls could have a history of any cancer other than AML and were matched for the year of birth, sex, and country. Persons with minimum age of 20 years at index date, and having occupational information from at least one census record, were included in the present study.

For each case and control, the exposure to solvents and other occupational factors was estimated based on conversions of occupational codes to quantitative amounts of exposures with the NOCCA job exposure matrix (JEM). National experts from the Nordic countries developed the NOCCA JEM on the basis of the Finnish JEM (13). It covers more than 300 specific occupations, 29 exposure agents and 4 periods: 1945-59, 1960-74, 1975-84, and 1985-94. Exposure agents are characterized by the proportion of exposed (P) and the mean level of exposure among the exposed persons (L) in a specific occupation and time period. The NOCCA JEM was described in detail in Kauppinen et al (14).

We quantified exposure to benzene, toluene, perchloroethylene, methylene chloride, trichloroethylene, and 1,1,1-trichloroethane as individual solvents; and aliphatic and alicyclic hydrocarbon solvents (ALHC), aromatic hydrocarbon solvents (ARHC), chlorinated hydrocarbon solvents (CHC), and other organic solvents (OSOL) as grouped solvents. In addition to this, we
Table 1. Individual/grouped solvents and co-factors with measurement units. [PPM= parts per million of agent; $\mathrm{mg} / \mathrm{m3}=$ milligram of agent in cubic of workroom air; $\mathrm{f} / \mathrm{cm} 3=$ fibers of asbestos in cubic centimeter of workroom air; $\mu \mathrm{g} / \mathrm{m} 3=$ microgram of agent in cubic meter of workroom air; $\mu \mathrm{mol} / \mathrm{l}=$ micromoles of lead in liter of blood; $\mathrm{mSv}=$ annual equivalent radiation dose in millisieverts.]

\begin{tabular}{ll}
\hline Agent & Unit \\
\hline Solvent & \\
Aliphatic and alicyclic hydrocarbon solvents & $\mathrm{ppm}$ \\
Aromatic hydrocarbon solvents & $\mathrm{ppm}$ \\
Benzene & $\mathrm{ppm}$ \\
Toluene & $\mathrm{ppm}$ \\
Chlorinated hydrocarbon solvents & $\mathrm{ppm}$ \\
Methylene chloride & $\mathrm{ppm}$ \\
Perchloroethylene & $\mathrm{ppm}$ \\
Trichloroethylene & $\mathrm{ppm}$ \\
1,1,1-trichloroethane & $\mathrm{ppm}$ \\
Other organic solvents & $\mathrm{ppm}$ \\
Co-factor & \\
Animal dust & $\mathrm{mg} / \mathrm{m}^{3}$ \\
Asbestos & $\mathrm{f} / \mathrm{cm}$ \\
Benzo(a)pyrene & $\mu \mathrm{g} / \mathrm{m}^{3}$ \\
Bitumen fumes & $\mathrm{mg} / \mathrm{m}^{3}$ \\
Chromium & $\mu \mathrm{g} / \mathrm{m}^{3}$ \\
Diesel engine exhaust & $\mathrm{mg} / \mathrm{m}^{3}$ \\
Iron & $\mathrm{mg} / \mathrm{m}^{3}$ \\
Formaldehyde & $\mathrm{ppm}$ \\
Gasoline & $\mathrm{ppm}$ \\
Nickel & $\mu \mathrm{g} / \mathrm{m}^{3}$ \\
Lead & $\mu \mathrm{mol} / \mathrm{l}$ \\
Quartz dust & $\mathrm{mg} / \mathrm{m}^{3}$ \\
Sulphur dioxide & $\mathrm{ppm}$ \\
Ionizing radiation & $\mathrm{mSv}$ \\
Wood dust & $\mathrm{mg} / \mathrm{m}^{3}$ \\
Welding fumes & $\mathrm{mg} / \mathrm{m}^{3}$ \\
\hline &
\end{tabular}

quantified exposure to 16 other agents which were considered as potential co-factors in the analysis (table 1).

The procedure for quantifying cumulative exposure was as follows. For each occupational code, a corresponding value of the product of proportion and level of exposure $(\mathrm{P} \times \mathrm{L})$ from NOCCA JEM file was assigned. This value was then multiplied by employment period $(\mathrm{T})$ in years during which the subject was in that occupation. The procedure was repeated for all exposure factors.

Employment period was assumed to start at the age of 20 and end at 65 years. If there were different occupational codes in census records for a given person, the individual was assumed to have changed occupation in the middle of the known census years. In such a case, the exposure history of the persons consisted of more than one $\mathrm{P} \times \mathrm{L} \times \mathrm{T}$ value. Cumulative exposure for these individuals was estimated by summing up all of their $\mathrm{P} \times \mathrm{L} \times \mathrm{T}$ values over the entire working career. Assuming that AML develops over a number of years, and recent exposures are less relevant than those which took place in the past, we conducted main analyses in which all exposures that occurred during the last ten years before the index date were not counted. 
We estimated hazard ratios (HR) and 95\% confidence intervals $(95 \% \mathrm{CI})$ for each solvent by conditional logistic regression. We selected values corresponding to the $50^{\text {th }}$ and $90^{\text {th }}$ percentiles of cumulative exposure distribution among all exposed case/control subjects as cut-off points for categorization. We defined exposure values of $0-50^{\text {th }}$ percentile inclusive as "low", $50-90^{\text {th }}$ percentile inclusive as "moderate", and $>90$ th percentile of exposure distribution as "high". Individuals with 0 exposure were used as the reference group. Test for trend was performed for a dose-response relationship between exposure factors and AML.

Variable selection for the final main-effect models was based-on the "purposeful covariate selection" procedure (15). Benzene and toluene were highly correlated with ARHC. Therefore, we selected two alternative main-effect models. In Model 1, we included benzene and toluene but not ARHC; and in Model 2, we included ARCH but neither benzene nor toluene. All other solvents were included in both models, and they were also adjusted for ionizing radiation and formaldehyde as co-factors. The results from both models were similar. Therefore, we present only the results of Model 1, except for the ARHC results, which can only come from Model 2.

Analyses stratified by age and sex was conducted to explore potential age- and sex-specific interactions with exposure. Age at index was categorized into two broad levels: $<50$ and $\geq 50$ years, because only a small proportion of subjects $(11-12 \%)$ were $<50$ years (table 2 ).

Finally, all analyses were done with different lagtime assumptions $(0,3,5,7,10$, and 20 years $)$.

\section{Results}

Altogether, 15332 cases and 76660 controls were identified during the study period (table 2). Of these, 350 cases $(2.3 \%)$ and 2155 controls $(2.8 \%)$ were excluded because they were either $<20$ years or had no occupational record. The proportion of male subjects was $52 \%$, and $45 \%$ of the cases and controls were from Sweden. About $90 \%$ of case/controls were born before 1940, and the mean age at AML diagnosis was about 67 years (table 2).

We did not observe statistically significantly increased risk or dose-response relationship for any solvent exposure and AML (table 3). The highest risk estimate was observed for toluene levels $>90^{\text {th }}$ percentile of exposure distribution (HR 1.35, 95\% CI 0.74-2.46). Risk estimates associated with exposure to high levels of ARHC and high and moderate levels of trichloroethylene were slightly elevated. Similarly, a small increase in risk estimates for exposure to high levels of ionizing radiation and formaldehyde were also observed.
Table 2. Demographic characteristics of acute myeloid leukemia cases and controls.

\begin{tabular}{|c|c|c|c|c|}
\hline \multirow[t]{2}{*}{ Characteristic } & \multicolumn{2}{|c|}{ Cases } & \multicolumn{2}{|c|}{ Controls } \\
\hline & $\mathrm{N}$ & $\%$ & $\mathrm{~N}$ & $\%$ \\
\hline \multicolumn{5}{|l|}{ Sex } \\
\hline Male & 7751 & 51.7 & 38642 & 51.9 \\
\hline Female & 7231 & 48.3 & 35863 & 48.1 \\
\hline \multicolumn{5}{|l|}{ Country } \\
\hline Finland & 3484 & 23.3 & 17419 & 23.4 \\
\hline Iceland & 109 & 0.7 & 479 & 0.6 \\
\hline Norway & 4606 & 30.7 & 22928 & 30.8 \\
\hline Sweden & 6783 & 45.3 & 33679 & 45.2 \\
\hline \multicolumn{5}{|c|}{ Age at index date a } \\
\hline $20-29$ & 139 & 0.9 & 690 & 0.9 \\
\hline 30-39 & 458 & 3.1 & 2271 & 3.1 \\
\hline $40-49$ & 1163 & 7.8 & 5758 & 7.7 \\
\hline $50-59$ & 1991 & 13.3 & 9881 & 13.3 \\
\hline $60-69$ & 3558 & 23.8 & 17687 & 23.7 \\
\hline $70-79$ & 4836 & 32.3 & 24089 & 32.3 \\
\hline$\geq 80$ & 2837 & 18.9 & 14129 & 18.9 \\
\hline \multicolumn{5}{|l|}{ Year of birth } \\
\hline$\leq 1910$ & 3350 & 22.4 & 16682 & 22.4 \\
\hline 1911-1920 & 4042 & 26.9 & 20138 & 27.0 \\
\hline $1921-1930$ & 3677 & 24.5 & 18293 & 24.6 \\
\hline 1931-1940 & 2000 & 13.4 & 9926 & 13.3 \\
\hline 1941-1950 & 1406 & 9.4 & 6975 & 9.4 \\
\hline 1951-1960 & 507 & 3.4 & 2491 & 3.3 \\
\hline Total & 14982 & 100 & 74505 & 100 \\
\hline
\end{tabular}

${ }^{a}$ Index date is defined as a date of diagnoses for the case and a date of diagnoses of the matched case for the control within each risk set.

Sex-specific risk estimates associated with exposure to high levels of toluene were higher among men than women (table 4). In contrast, HR estimates for ARHC, benzene, methylene chloride, and trichloroethylene were more pronounced among women than men.

Analysis stratified on age showed that HR estimates of AML associated with exposure to some solvents might be higher in younger ages (table 5). For example, the risk of AML was more than two-fold among benzeneand methylene-chloride-exposed individuals $<50$ years, whereas it was close to one among those $\geq 50$ years.

Analysis with different lag-time assumptions showed that HR estimates for toluene were 1.86 (95\% CI 1.06$3.28)$ with 0 lag-time and 1.62 (95\% CI $0.89-2.96)$ with 20 year lag-time. HR for ARHC and trichloroethylene remained elevated from $0-10$-year-lag-time and decreased towards null with 20-year-lag-time (data not shown).

\section{Discussion}

The results from this study showed some suggestive evidence for an association between AML and solvent exposure but not consistently in both genders. There was non-significant excess risk for toluene, ARHC, and 
Table 3. Hazard ratios (HR) and 95\% confidence intervals (95\% $\mathrm{CI})$ of acute myeloid leukemia associated with exposure to solvents and other co-factors. [Ppm=parts per million; $\mathrm{mSv}=$ millisieverts].

\begin{tabular}{|c|c|c|c|c|c|}
\hline Agent a (ppm/year) & Cases & Controls & $\mathrm{HR}$ & $95 \% \mathrm{Cl}$ & $\begin{array}{l}\text { P-value } \\
\text { for trend }\end{array}$ \\
\hline \multicolumn{6}{|c|}{$\begin{array}{l}\text { Aliphatic and alicyclic } \\
\text { hydrocarbon solvents }\end{array}$} \\
\hline$\leq 17.5$ & 353 & 1743 & 1.01 & $0.79-1.29$ & \\
\hline $17.5-300$ & 283 & 1393 & 1.08 & $0.82-1.42$ & \\
\hline$>300$ & 54 & 366 & 0.64 & $0.38-1.08$ & 0.76 \\
\hline \multicolumn{6}{|c|}{$\begin{array}{l}\text { Aromatic hydrocarbon } \\
\text { solvents }{ }^{b}\end{array}$} \\
\hline$\leq 9.3$ & 362 & 1661 & 1.10 & $0.98-1.25$ & \\
\hline $9.3-275$ & 256 & 1362 & 0.99 & $0.80-1.24$ & \\
\hline$>275$ & 63 & 342 & 1.18 & $0.76-1.86$ & 0.56 \\
\hline \multicolumn{6}{|l|}{ Benzene } \\
\hline$\leq 3.7$ & 430 & 1999 & 1.02 & $0.84-1.24$ & \\
\hline $3.7-13.6$ & 310 & 1633 & 0.88 & $0.71-1.11$ & \\
\hline$>13.6$ & 68 & 418 & 0.80 & $0.56-1.15$ & 0.33 \\
\hline \multicolumn{6}{|l|}{ Toluene } \\
\hline$\leq 42.4$ & 424 & 1954 & 1.17 & $0.94-1.45$ & \\
\hline $42.4-61$ & 296 & 1602 & 1.01 & $0.79-1.30$ & \\
\hline$>612$ & 76 & 400 & 1.35 & $0.74-2.46$ & 0.49 \\
\hline \multicolumn{6}{|l|}{ Trichloroethylene } \\
\hline$\leq 16.2$ & 302 & 1760 & 0.93 & $0.79-1.09$ & \\
\hline $16.2-121$ & 275 & 1373 & 1.12 & $0.94-1.33$ & \\
\hline$>121$ & 68 & 345 & 1.12 & $0.83-1.49$ & 0.08 \\
\hline \multicolumn{6}{|c|}{ 1,1,1-trichloroethane } \\
\hline$\leq 5.6$ & 566 & 2986 & 0.89 & $0.76-1.04$ & \\
\hline $5.6-12.7$ & 244 & 1317 & 0.86 & $0.71-1.05$ & \\
\hline$>12.7$ & 86 & 482 & 0.81 & $0.61-1.08$ & 0.58 \\
\hline \multicolumn{6}{|l|}{ Methylene chloride } \\
\hline$\leq 9.9$ & 326 & 1638 & 1.01 & $0.82-1.25$ & \\
\hline $9.9-64.6$ & 249 & 1267 & 1.06 & $0.84-1.34$ & \\
\hline$>64.6$ & 59 & 328 & 1.06 & $0.58-1.94$ & 0.43 \\
\hline \multicolumn{6}{|l|}{ Perchloroethylene } \\
\hline$\leq 12.1$ & 89 & 472 & 1.07 & $0.83-1.38$ & \\
\hline $12.1-106$ & 67 & 381 & 0.83 & $0.61-1.12$ & \\
\hline$>106$ & 16 & 96 & 0.72 & $0.39-1.34$ & 0.39 \\
\hline \multicolumn{6}{|c|}{ Other organic solvents } \\
\hline$\leq 83.8$ & 167 & 760 & 1.09 & $0.90-1.33$ & \\
\hline $83.8-357$ & 123 & 617 & 0.96 & $0.71-1.30$ & \\
\hline$>357$ & 28 & 158 & 1.08 & $0.61-1.90$ & 0.48 \\
\hline \multicolumn{6}{|c|}{$\begin{array}{l}\text { Co-factor } \\
\text { lonizing radiation (mSv/year) }\end{array}$} \\
\hline & 27 & & 0.84 & $0.56-1.27$ & \\
\hline $3.6-12.5$ & 27 & 121 & 1.09 & $0.72-1.67$ & \\
\hline$>2.5$ & 7 & 31 & 1.12 & $0.49-2.55$ & 0.89 \\
\hline \multicolumn{6}{|l|}{ Formaldehyde } \\
\hline$\leq 0.171$ & 580 & 3241 & 0.89 & $0.81-0.97$ & \\
\hline $0.171-1.6$ & 485 & 2571 & 0.92 & $0.83-1.03$ & \\
\hline$>1.6$ & 136 & 628 & 1.17 & $0.91-1.51$ & 0.07 \\
\hline
\end{tabular}

a Occupationally unexposed individuals were used as a reference group in all analyses.

${ }^{b}$ HR estimates for aromatic hydrocarbon solvents are from Model 2, all other HR are from Model 1. trichloroethylene. We did not observe an association between exposure to benzene and AML unlike many earlier studies (4-8).

The evidence for an increased risk of AML from exposure to organic solvents other than benzene is inconsistent. The recent studies by Kaufman et al (10) and Strom et al (11) suggested an increased risk of AML following solvent exposure. However, both studies had limitations with exposure assessment. In the former study, the authors combined benzene, gasoline, and other solvents into a single group due to a small number of exposed subjects. In the latter, exposure information was collected via personal interviews and was, therefore, subject to a recall bias. In an Italian multicenter case-control study no association between exposure to solvents and AML was found (16). Excess risk of AML from benzene exposure could be identifiable already at $10 \mathrm{ppm} / \mathrm{year}$ exposure levels according to Vlaanderen et al (8). The estimated cumulative benzene exposure in our study exceeded $13.6 \mathrm{ppm} /$ year for 68 cases and 418 controls (table 3 ). These numbers are so high that our study is unlikely to lack power and miss an effect should one exist in our data.

Observed age and sex-specific variation in risk estimates could result from effect of physiological differences by age and sex on pharmacokinetics (absorption, distribution, metabolism, elimination) of solvents (17-21). However, we cannot exclude the possibility of chance findings.

When interpreting our results, the following limitations need to be considered. Because this study was based on general populations of the Nordic countries, only a small percentage of study population had considerable exposure to solvents. This constrained our choice of cumulative exposure categorization. Another potential limitation of the present study is exposure misclassification, which may arise from two sources. First, the generic JEM has a poor sensitivity and a failure to account for heterogeneity in exposure levels within jobs $(22,23)$. Work history data is a second factor likely to contribute to exposure misclassification. Individual work histories were based on census records that are a snapshot of a job held by individual at the time of the census. The data did not provide information on the changes of the job or tasks during the entire working career of an individual. In this study, we assumed that an individual held his/her occupation until the mid-year between two censuses. Finally, we could not control for smoking and genetic factors that have previously been linked to AML (24-27). However, lung cancer risk was not elevated in the majority of occupational groups with solvent exposure (12), suggesting that the smoking rate among solvent-exposed individuals was unlikely to be higher than the general population. In addition, genetic factors are very rare and unlikely to be related to solvent exposure. Therefore, smoking and 
Table 4. Sex-specific hazard ratios (HR) and 95\% confidence intervals $(95 \% \mathrm{Cl})$ of acute myeloid leukemia associated with exposure to solvents with sex-specific variation of HR estimates. [ppm=parts per million].

\begin{tabular}{|c|c|c|c|c|c|c|c|c|c|c|}
\hline \multirow[t]{2}{*}{ Agent a (ppm/year) } & \multicolumn{5}{|c|}{ Males } & \multicolumn{5}{|c|}{ Females } \\
\hline & Cases & Controls & $\mathrm{HR}$ & $95 \% \mathrm{Cl}$ & $\begin{array}{l}\text { P-value } \\
\text { for trend }\end{array}$ & Cases & Controls & $\mathrm{HR}$ & $95 \% \mathrm{Cl}$ & $\begin{array}{l}\text { P-value } \\
\text { for trend }\end{array}$ \\
\hline \multicolumn{11}{|c|}{ Aromatic hydrocarbon solvents ${ }^{b}$} \\
\hline$\leq 9.3$ & 265 & 1182 & 1.14 & $0.99-1.32$ & & 97 & 479 & 1.04 & $0.81-1.32$ & \\
\hline $9.3-275$ & 197 & 1000 & 1.02 & $0.79-1.30$ & & 59 & 362 & 1.13 & $0.62-2.03$ & \\
\hline$>275$ & 52 & 296 & 1.17 & $0.67-2.02$ & 0.49 & 11 & 46 & 1.67 & $0.71-3.96$ & 0.72 \\
\hline \multicolumn{11}{|l|}{ Benzene } \\
\hline$\leq 3.7$ & 350 & 1515 & 1.12 & $0.87-1.44$ & & 81 & 486 & 0.86 & $0.60-1.22$ & \\
\hline $3.7-13.6$ & 264 & 1414 & 0.89 & $0.69-1.18$ & & 45 & 213 & 1.10 & $0.69-1.74$ & \\
\hline$>13.6$ & 63 & 405 & 0.76 & $0.51-1.13$ & 0.18 & 5 & 17 & 2.02 & $0.58-7.04$ & 0.59 \\
\hline \multicolumn{11}{|l|}{ Toluene } \\
\hline$\leq 42.4$ & 366 & 1647 & 1.17 & $0.90-1.51$ & & 58 & 301 & 0.87 & $0.54-1.42$ & \\
\hline $42.4-61$ & 277 & 1483 & 1.02 & $0.77-1.36$ & & 19 & 125 & 0.63 & $0.29-1.31$ & \\
\hline$>612$ & 71 & 383 & 1.41 & $0.73-2.75$ & 0.32 & 5 & 17 & 0.85 & $0.17-4.35$ & 0.35 \\
\hline \multicolumn{11}{|l|}{ Trichloroethylene } \\
\hline$\leq 16.2$ & 239 & 1400 & 0.92 & $0.77-1.09$ & & 63 & 360 & 1.15 & $0.71-1.85$ & \\
\hline $16.2-121$ & 225 & 1117 & 1.09 & $0.91-1.32$ & & 50 & 258 & 1.41 & $0.85-2.36$ & \\
\hline$>121$ & 49 & 242 & 1.10 & $0.79-1.54$ & 0.08 & 19 & 101 & 1.52 & $0.71-3.26$ & 0.61 \\
\hline \multicolumn{11}{|l|}{ Methylene chloride } \\
\hline$\leq 9.9$ & 255 & 1301 & 0.99 & $0.76-1.28$ & & 41 & 201 & 1.24 & $0.79-1.96$ & \\
\hline $9.9-64.6$ & 258 & 1251 & 1.12 & $0.86-1.47$ & & 21 & 152 & 0.78 & $0.45-1.37$ & \\
\hline$>64.6$ & 58 & 326 & 1.14 & $0.59-2.19$ & 0.23 & 1 & 2 & 1.66 & $0.10-28.8$ & 0.58 \\
\hline
\end{tabular}

a Occupationally unexposed individuals were used as a reference group in all analyses.

${ }^{\mathrm{b}}$ HR estimates for aromatic hydrocarbon solvents are from Model 2, all other HR are from Model 1.

Table 5. Age-specific hazard ratios (HR) and 95\% confidence intervals (95\% Cl) of acute myeloid leukemia associated with exposure to solvents with age-specific variation of HR estimates. [ppm=parts per million].

\begin{tabular}{|c|c|c|c|c|c|c|c|c|c|c|}
\hline \multirow[t]{2}{*}{ Agent a (ppm/year) } & \multicolumn{5}{|c|}{$<50$ years } & \multicolumn{5}{|c|}{$\geq 50$ years } \\
\hline & Cases & Controls & $\mathrm{HR}$ & $95 \% \mathrm{Cl}$ & $\begin{array}{l}\mathrm{P} \text {-value } \\
\text { for trend }\end{array}$ & Cases & Controls & $\mathrm{HR}$ & $95 \% \mathrm{Cl}$ & $\begin{array}{l}\text { P-value } \\
\text { for trend }\end{array}$ \\
\hline \multicolumn{11}{|c|}{ Aromatic hydrocarbon solvents ${ }^{b}$} \\
\hline$\leq 3.3$ & 39 & 197 & 1.03 & $0.72-1.49$ & & 199 & 806 & 1.25 & $1.06-1.47$ & \\
\hline $3.3-110$ & 25 & 163 & 0.67 & $0.33-1.33$ & & 256 & 1389 & 0.95 & $0.80-1.11$ & \\
\hline$>110$ & 10 & 37 & 1.75 & $0.62-4.95$ & 0.94 & 152 & 773 & 1.05 & $0.72-1.54$ & 0.53 \\
\hline \multicolumn{11}{|l|}{ Benzene } \\
\hline$\leq 1.34$ & 55 & 255 & 1.07 & $0.66-1.71$ & & 173 & 836 & 1.05 & $0.82-1.36$ & \\
\hline $1.34-5$ & 29 & 219 & 0.69 & $0.36-1.29$ & & 222 & 1033 & 0.97 & $0.76-1.24$ & \\
\hline$>5$ & 18 & 44 & 2.24 & $0.99-5.08$ & 0.65 & 311 & 1663 & 0.82 & $0.63-1.07$ & 0.25 \\
\hline \multicolumn{11}{|l|}{ Toluene } \\
\hline$\leq 16.9$ & 47 & 252 & 0.96 & $0.49-1.88$ & & 213 & 1019 & 1.13 & $0.88-1.44$ & \\
\hline $16.9-220$ & 40 & 197 & 1.39 & $0.62-3.11$ & & 336 & 1601 & 1.33 & $1.01-1.75$ & \\
\hline$>220$ & 11 & 49 & 1.27 & $0.30-5.38$ & 0.63 & 149 & 838 & 0.78 & $0.53-1.15$ & 0.51 \\
\hline \multicolumn{11}{|l|}{ Trichloroethylene } \\
\hline$\leq 5.62$ & 38 & 229 & 0.84 & $0.53-1.35$ & & 88 & 562 & 0.87 & $0.66-1.14$ & \\
\hline $5.62-24.9$ & 35 & 178 & 1.03 & $0.65-1.64$ & & 194 & 1043 & 1.07 & $0.87-1.31$ & \\
\hline$>24.9$ & 11 & 43 & 1.28 & $0.62-2.63$ & 0.40 & 279 & 1423 & 1.08 & $0.90-1.29$ & 0.13 \\
\hline \multicolumn{11}{|l|}{ Methylene chloride } \\
\hline$\leq 5.58$ & 50 & 220 & 1.12 & $0.64-1.97$ & & 164 & 875 & 0.93 & $0.72-1.20$ & \\
\hline $5.58-17.5$ & 29 & 187 & 0.75 & $0.37-1.51$ & & 217 & 1067 & 1.05 & $0.81-1.36$ & \\
\hline$>17.5$ & 11 & 43 & 2.31 & $0.83-6.41$ & 0.76 & 163 & 841 & 1.15 & $0.84-1.57$ & 0.48 \\
\hline \multicolumn{11}{|c|}{ Other organic solvents } \\
\hline$\leq 33.6$ & 21 & 98 & 1.15 & $0.67-1.98$ & & 82 & 346 & 1.19 & $0.92-1.56$ & \\
\hline $33.6-144$ & 18 & 77 & 1.48 & $0.65-3.40$ & & 80 & 434 & 0.95 & $0.73-1.24$ & \\
\hline$>144$ & 3 & 21 & 0.88 & $0.18-4.25$ & 0.56 & 114 & 559 & 1.81 & $1.13-2.91$ & 0.58 \\
\hline
\end{tabular}

a Occupationally unexposed individuals were used as a reference group in all analyses.

${ }^{b}$ HR estimates for aromatic hydrocarbon solvents are from Model 2, all other HR are from Model 1. 
genetic factors could have only a little, if any, confounding effect on our estimates.

To our knowledge this was the largest study to assess the relationship between occupational exposure to solvents and AML, which covered the general populations of four Nordic countries. By linking occupational records to the NOCCA JEM, we were able to generate quantitative exposure estimates for 26 work-related agents. It enabled us to explore exposure-response relations beyond the analysis of crude categorization ("exposed" versus "non-exposed") or analysis by occupational groups. In addition, we were able to control for exposure to multiple agents and variation of exposure levels over time.

In conclusion, this study did not provide a clear evidence for an association between occupational solvent exposure and AML. There was some indication for an excess risk among those exposed to toluene, trichloroethylene, ARHC.

\section{Acknowledgments}

Doctoral Programs in Public Health (DPPH)/Academy of Finland funded a work implemented by the corresponding author. We thank Raili Salmelin for her statistical input.

The authors declare no conflicts of interests.

\section{References}

1. Sandler DP, Ross JA. Epidemiology of acute leukemia in children and adults. Semin Oncol. 1997;24(1):3-16.

2. Deschler B, Lubbert M. Acute Myeloid Leukemia: Epidemiology and Etiology. Cancer. 2006;107(9):2099-107. http://dx.doi.org/10.1002/cncr.22233.

3. Estey E, Döhner H. Acute myeloid leukaemia. Lancet. 2006;25:368(9550):1894-907. http://dx.doi.org/10.1016/ S0140-6736(06)69780-8.

4. Yin SN, Hayes RB, Linet MS, Li GL, Dosemeci M, Travis LB, et al. A cohort study of cancer among benzene-exposed workers in China: overall results. Am J Ind Med. 1996 Mar;29(3):227-35. http://dx.doi.org/10.1002/(SICI)10970274(199603)29:3<227::AID-AJIM2>3.0.CO;2-N.

5. Guenel P, Imbernon E, Chevalier A, Crinquand-Calastreng A, Goldberg M. Leukemia in Relation to Occupational Exposures to Benzene and Other Agents: A Case-Control Study Nested in a Cohort of Gas and Electric Utility Workers. Am J Ind Med. 2002 Aug;42(2):87-97. http://dx.doi.org/10.1002/ ajim. 10090 .

6. Khalade A, Jaakkola MS, Pukkala E, Jaakkola JJK. Exposure to benzene at work and the risk of leukemia: a systematic review and meta-analysis. Environ Health. 2010;9:31. http:// dx.doi.org/10.1186/1476-069X-9-31.

7. Vlaanderen J, Lan Q, Kromhout H, Rothman N, Vermeulen R. Occupational Benzene Exposure and the Risk of Chronic Myeloid Leukemia: A Meta-Analysis of Cohort Studies Incorporating Study Quality Dimensions. Am J Ind Med. 2012 Sep;55(9):779-85. http://dx.doi.org/10.1002/ajim.22087.

8. Vlaanderen J, Portengen L, Rothman N, Lan Q, Kromhout H, Vermeulen R. Flexible Meta-Regression to Assess the Shape of the Benzene-Leukemia Exposure-Response Curve. Environ Health Perspect. 2010 Apr; 118(4):526-32. http://dx.doi. org/10.1289/ehp.0901127.

9. Blair A, Zheng T, Linos A, Stewart PA, Zhang YW, Cantor KP. Occupation and Leukemia: A Population-Based CaseControl Study in Iowa and Minnesota. Am J Ind Med. 2001 Jul;40(1):3-14. http://dx.doi.org/10.1002/ajim.1066.

10. Kaufman DW, Anderson TE, Issaragrisil S. Risk factors for leukemia in Thailand. Ann Hematol. 2009 Nov;88(11):1079 88. http://dx.doi.org/10.1007/s00277-009-0731-9.

11. Strom SS, Oum R, Kplola Y. Elhor Gbito, Guillermo GM, Yamamura Y. De Novo Acute Myeloid Leukemia Risk Factors: A Texas Case-Control Study. Cancer. 2012;118(18)4589-96. http://dx.doi.org/10.1002/cncr.27442.

12. Pukkala E, Martinsen JI, Lynge E, Gunnarsdottir HK, Sparen P, Tryggvadottir L, et al. Occupation and cancer - follow-up of 15 million people in five Nordic countries. Acta Oncol. 2009;48(5):646-790. http://dx.doi. org/10.1080/02841860902913546.

13. Kauppinen T, Toikkanen J, Pukkala E. From crosstabulations to multipurpose exposure information systems: a new job-exposure matrix. Am J Ind Med. 1998 Apr; 33(4):409-17. http://dx.doi.org/10.1002/(SICI) 1097 0274(199804)33:4<409::AID-AJIM12>3.0.CO;2-2.

14. Kauppinen T, Heikkilä P, Plato N, Woldbaek T, Lenvik $\mathrm{K}$, Hansen J, et al. Construction of job-exposure matrices for the Nordic Occupational Cancer Study (NOCCA). Acta Oncol. 2009;48(5):791-800. http://dx.doi. org/10.1080/02841860902718747.

15. Hosmer D, Lemeshow S. Applied Logistic Regression. 2nd ed. New York:John Wiley \& Sons;2004.

16. Costantini SA, Benvenuti A, Vineis P, Kriebel D, Tumino R, Ramazzotti V, et al. Risk of Leukemia and Multiple Myeloma Associated With Exposure to Benzene and Other Organic Solvents: Evidence From the Italian Multicenter Case-Control Study. Am J Ind Med. 2008 Nov;51(11):803-11. http://dx.doi. org/10.1002/ajim.20592.

17. Clewell HJ, Gentry PR, Covington TR, Sarangapani R, Teeguarden JG. Evaluation of the Potential Impact of Ageand Gender-Specific Pharmacokinetic Differences on Tissue Dosimetry. Toxicol Sci. 2004 Jun;79(2):381-93. http://dx.doi. org/10.1093/toxsci/kfh109.

18. Roskos KV, Maibach HI, Guy RH. The effect of aging on percutaneous absorption in man. J of Pharmacokinet Biopharm. 1989 Dec;17(6):617-30. http://dx.doi.org/10.1007/ BF01062121. 
19. Kim Cs, Hu SC. Regional deposition of inhaled particles in human lungs: comparison between men and women. J Appl Physiol. 1998 Jun;84(6):1834-44.

20. Beierle I, Meibohm B, Derendorf H. Gender differences in pharmacokinetics and pharmacodynamics. Int $\mathrm{J}$ Clin Pharmacol Ther. 1999 Nov;37(11):529-47.

21. Parkinson A, Ogilvie BW, Buckley DB, Kazmi F, Czerwinski $\mathrm{M}$, Parkinson O. Biotransformation of xenobiotics. In: Klaasen, C, editors. Casarett and Doull's Toxicology: The Basic Sciences of Poisons. 8th ed. New-York: McGraw-Hill Professional; 2013. p. 185-367.

22. Friesen MC, Coble JB, Lu W, Xiao-Ou Shu, Bu-Tian Ji, Shouzheng Xue, et al. Combining a Job-Exposure Matrix with Exposure Measurements to Assess Occupational Exposure to Benzene in a Population Cohort in Shanghai, China. Ann Occup Hyg. 2012 Jan;56(1):80-91. http://dx.doi.org/10.1093/ annhyg/mer080.

23. Scott CS, Chiu WA. Trichloroethylene cancer epidemiology: a consideration of select issues. Environ Health Perspect. 2006 Sep;114(9):1471-8. http://dx.doi.org/10.1289/ehp.8949.
24. Pogoda JM, Preston-Martin S, Nichols PW, Ross RK. Smoking and risk of acute myeloid leukemia: results from a Los-Angeles County case-control study. Am J Epidemiol. 2002 Mar 15;155(6):546-53. http://dx.doi.org/10.1093/ aje/155.6.546.

25. Kasim K, Levallois P, Abdous B, Auger P, Johnson KC. Lifestyle factors and the risk of adult leukaemia in Canada. Cancer Causes Control. 2005 Jun;16(5):489-500. http:// dx.doi.org/10.1007/s10552-004-7115-1.

26. Bowen DT, Frew ME, Rollinson S, Roddam PL, Dring A, Smith MT, et al. CYP1A1*2B (Val) allele is overrepresented in a subgroup of acute myeloid leukemia patients with poor-risk karyotype associated with NRAS mutation, but not associated with FLT3 internal tandem duplication. Blood. 2003;101(7):2770-4. http://dx.doi.org/10.1182/ blood-2002-01-0228.

27. Smith MT, Yunxia Wang, Kane E, Rollinson S, Wiemels JL, Roman E, et al. Low NAD(P)H:quinoneoxidoreductase 1 activity is associated with increased risk of acute leukemia in adults. Blood. 2001;97(5):1422-6. http://dx.doi.org/10.1182/ blood.V97.5.1422.

Received for publication: 4 December 2014 